\title{
The Effect of H-Bonding on Radical Copolymerization of Maleic Anhydride with N-tert-Butylacrylamide and Its Characterization
}

\author{
Ahmet Okudan and Ayşe Karasakal \\ Department of Chemistry, Selcuk University, 42075 Konya, Turkey \\ Correspondence should be addressed to Ahmet Okudan; okudan1@gmail.com
}

Received 31 July 2013; Revised 7 October 2013; Accepted 13 October 2013

Academic Editor: Jose Ramon Leiza

Copyright ( 2013 A. Okudan and A. Karasakal. This is an open access article distributed under the Creative Commons Attribution License, which permits unrestricted use, distribution, and reproduction in any medium, provided the original work is properly cited.

\begin{abstract}
The copolymerization reaction between N-tert-butylacrylamide (NTBA) and maleic anhydride (MA) in $p$-dioxane solution at $65^{\circ} \mathrm{C}$ using $2,2^{\prime}$-azoisobutyronitrile (AIBN) as an initiator in nitrogen atmosphere was carried out. The chemical structure of the obtained copolymers from a wide range of monomer feeds was determined by elemental analysis (content of N for NTBA units), Fourier transform infrared (FTIR), and 1H-NMR spectroscopy. Also, the amounts of MA units in the copolymers were found using the chemical titration method. An observed tendency toward alternating copolymerization at $\leq 50 \mathrm{~mol} \%$ NTBA concentration in monomer feed and relatively high activity of NTBA growing radical was explained by $\mathrm{H}$-bond formation between $\mathrm{C}=\mathrm{O}$ (anhydride) and $\mathrm{NH}$ (amide) fragments during chain growth reactions. Intrinsic viscosity and the molecular weights of the synthesized copolymers depend on the type of comonomer and the amount of NTBA units in the copolymers. The synthesized poly(NTBA-MA)s containing a functional amphiphilic group show both temperature and $\mathrm{pH}$ sensitivity and can be used for biological proposes as a physiologically active macromolecular system.
\end{abstract}

\section{Introduction}

Copolymer is the most successful and powerful method for effecting a systematic change in polymer [1]. Studies have shown that the copolymerization reactions provide an excellent way to prepare macromolecules with specific chemical structures and to control properties such as hydrophilic/hydrophobic balances, polarity, and solubility [2]. Many polymers with reactive functional groups are now being synthesized, tested, and used not only for the macromolecular properties but also for the properties of functional groups. These functional groups provide an approach to a subsequent modification of the polymers for a specific end application [3]. An anhydride group containing maleic anhydride and its polymers has received considerable attention recently because of its varied applications. Maleic anhydride cannot be homopolymerized under normal conditions [4] or hardly homopropagates, which means that maleic anhydridemaleic anhydride diads are virtually absent in the polymer chain [5]. Nevertheless, the reactive MA moiety provides the copolymers with a wide variety of options for chemical modification [6]. Furthermore, it is generally accepted that copolymerization shows a strong tendency toward alternation [7]. Acrylamide and its derivatives can undergo alternating copolymerization with maleic anhydride under the given conditions [8-18]. Due to this complex formation, the alternating copolymerization of the monomers can be initiated by a free radical mechanism. The reaction products are alternating copolymers providing high polarity and mechanical and thermal stability [19]. In this study, MA, which contains two adjacent carboxylic acid groups in anhydride form and reactive carbonyl groups that may be subjected to numerous reactions, was selected for polymerizations with NTBA.

Hydrogen bonding is one of the important noncovalent interactions in nature. The bonding energies for normal hydrogen bonds are between $10-50 \mathrm{~kJ} / \mathrm{mol}$. These stable and dynamic molecular complexes can be prepared by simple molecular self-assembly processes using such hydrogen [20]. For design of synthetic polymers, hydrogen bonding has not been considered to be very useful. If varieties of hydrogen bonding moieties are strategically introduced into synthetic polymeric and organic materials, new polymeric materials 
exhibiting a variety of functions can be obtained. Peculiarities of H-complex formation in the monomer-monomer and monomer-solvent systems give the opportunity to design new polyfunctional co- and terpolymers [21].

The reactive maleic anhydride moiety provides the copolymers with a wide variety of options for chemical modification. Depending on the requirement, many of the maleic anhydride copolymers can be modified by a reaction at the maleic anhydride ring $[22,23]$. Those copolymers are potentially useful as flocculants, for purification of industrial waste water, and as coatings for microcapsule production and paper dry-strength agents [14]. Also, these functional amphiphilic copolymers containing anion- and cation-active groups show both temperature and $\mathrm{pH}$ sensitivity and can be used for biological purposes as physiologically active macromolecular systems. Alternating copolymers of maleic anhydride can be regarded as preactivated polymers due to the presence of anhydride moieties susceptible to the reaction with a primary amine of a biomolecule [24]. Numerous water-soluble polymers for the most part acrylic derivatives and vinyl type polymers have been investigated for use as macromolecular drug carriers [25], protein hybrids [26] and advanced applications in biotechnology [6]. Also, in Trivedi and Culbertson [14], maleic anhydride copolymers are used for many purposes according to a detailed summary of their application. Recently, the synthesis and characterization of cationic stimuli-responsive containing acrylamide derivatives as potentially useful as carriers for gene delivery, conjugates of polyacrylamide derivatives with amino acids as prodings, and antitumor active binary and ternary copolymers of maleic anhydride and acrylic acid (or 2,3-dihydropyran) have been reported $[27,28]$.

This study has investigated the results of the synthesis and characterization of poly(NTBA-co-MA)s with different compositions by the radical-initiated solution copolymerization of NTBA and MA in a wide range of monomer ratios as a way to obtain new reactive amphiphilic polymers that are potentially useful as carriers for gene delivery. The effect of $\mathrm{H}$-bond formation in between the $-\mathrm{C}=\mathrm{O}$ groups of maleic anhydride with $-\mathrm{NH}$ groups of the $\mathrm{N}$-tert-butyl acrylamide on the copolymer composition-properties relationship has been described and discussed. The synthesized copolymers were characterized by IR-spectroscopy, ${ }^{1} \mathrm{H}-\mathrm{NMR}$, elemental analysis, gel permeation chromatography (GPC), and chemical titration.

\section{Experimental Section}

2.1. Materials. Maleic anhydride (MA) (Fluka) was purified by recrystallization from anhydrous benzene and by sublimation in vacuo, m.p. $=52.8^{\circ} \mathrm{C} . \mathrm{N}$-tert-butylacrylamide $(\mathrm{NTBA})$ (Aldrich) was recrystallized in warm dry benzene. $2,2^{\prime}$ Azoisobutyronitrile (AIBN) (Fluka) was twice recrystallized from methanol: m.p. $=102.5^{\circ} \mathrm{C}$. $p$-Dioxane (Merck) was refluxed over sodium and distilled from aluminum lithium hydride. The middle fraction was used. All other reagents were used without further purification.

\subsection{NTBA-MA Copolymer}

2.2.1. Synthesis of NTBA-MA Copolymer. For the synthesis of an NTBA-MA copolymer, various molar ratios of NTBA and MA were dissolved in $p$-dioxane in a round-bottom flask equipped with a magnetic stir bar and in a thermostated silicon oil bath at $65 \pm 0.1^{\circ} \mathrm{C}$ and a nitrogen inlet. Reaction conditions are $[\mathrm{M}]$ total $=1.33 \mathrm{~mol} / \mathrm{L},[\mathrm{AIBN}]=6.6 \times$ $10^{-4} \mathrm{~mol} / \mathrm{L}$, and monomer ratios of $[\mathrm{NTBA}] /[\mathrm{MA}]=0.43-$ 2.33. The balance amount of NTBA was introduced in four doses after every 45 minutes. Each dosing was accompanied by degassing with nitrogen for 5 minutes. The polymerization was continued for approximately 24 hours. After the polymerizations were completed, the NTBA-MA copolymers were separated from the reaction mixture by precipitation in diethyl ether, which was a solvent for these two monomers and the NTBA homopolymer at room temperature. The products were obtained as white powder. Then, the products obtained were redissolved in $p$-dioxane and reprecipitated by diethyl ether and washed several times with diethyl ether. The insoluble copolymer was removed by filtration and dried in a vacuum oven at $50^{\circ} \mathrm{C}$ for at least 2 days. Monomer unit ratio, $m_{1}: m_{2}=47.6: 52.4$; content of $\mathrm{N}=6.52 \%$ (by elemental analysis); acid number $412 \mathrm{mg} \mathrm{KOH} / \mathrm{g} ;[\eta]_{\text {in }}=0.097 \mathrm{~g} / \mathrm{dL}$ in THF at $25 \pm 0.1^{\circ} \mathrm{C} ; M_{n}=6100$ (by GPC).

2.2.2. The Determination of Monomer Reactivity Ratios. To the determine the monomer reactivity ratios, the copolymerization of NTBA with MA using various monomer feed ratios was carried out in $p$-dioxane by free radical copolymerization in the presence of AIBN as an initiator in nitrogen inlet. To determine monomer reactivity ratios, NTBA-MA copolymers were synthesized in glass ampoules sealed with rubber septa using $p$-dioxane as a solvent and AIBN as an initiator. The total monomer and initiator concentrations were kept at $1.33 \mathrm{~mol} / \mathrm{L}$ and $6.6 \times 10^{-4} \mathrm{~mol} / \mathrm{L}$, respectively. Dissolved oxygen was removed from the reaction solution by nitrogen purging for 30 minutes before immersion in a water bath at $65^{\circ} \mathrm{C} \pm 0.1^{\circ} \mathrm{C}$. The copolymerization system was homogeneous in all the cases investigated. After a specific length of time, each ampoule was removed from the water bath, and the reaction was stopped with $0.5 \mathrm{~mL}$ of a $10 \mathrm{wt} . \%$ solution of hydroquinone in $p$-dioxane. The polymerization was continued for approximately 3 hours. Diethyl ether was used to isolate the copolymers. All samples were purified by reprecipitation using $p$-dioxane as the solvent and diethyl ether as the precipitant and then dried in a vacuum oven at $50^{\circ} \mathrm{C}$ for at least 2 days.

2.3. Copolymer Characterization. The copolymer compositions were found by elemental ( $\mathrm{N}$ content for NTBA units) and chemical (acid number for anhydride units) FTIR and ${ }^{1} \mathrm{H}$ NMR spectroscopy using an integral area of chemical shifts of monomer functional groups for quantitative analysis.

The absorption value ratios between characteristic analytical bands of $1658 \mathrm{~cm}^{-1}$ (for band in NTBA unit), $1775 \mathrm{~cm}^{-1}$ (for $\mathrm{C}=\mathrm{O}$ band in $\mathrm{MA}$ unit) and the least changing absorption band of $1365 \mathrm{~cm}^{-1}$ as a standard band $\left(A=\log \left(I / I_{o}\right)\right.$, 
$\Delta A^{i}=A^{i} / A^{1365}$ ) were used to calculate the copolymer composition. Molar fractions (in mol\%) of comonomer units $\left(m_{1}\right.$ and $m_{2}$ ) in copolymer using FTIR analysis data are calculated according to following equation:

$$
\frac{m_{1}}{m_{2}}=\left(\frac{\Delta A m_{1}^{1658}}{\Delta A m_{2}^{1775}}\right) \times\left(\frac{M_{1}}{M_{2}}\right),
$$

where $M_{1}$ and $M_{2}$ are molecular weights of NTBA and MA monomer units, respectively.

The compositions of the copolymers synthesized were determined by comparing the integrals of the tert-butyl and methyne group regions in the spectra of NTBA and MA units, respectively. The molar fractions of the comonomer units $\left(m_{1}\right.$ and $m_{2}$ ) in NTBA-MA copolymers using ${ }^{1} \mathrm{H}$ NMR analysis data were calculated according to the following equations:

$$
\begin{gathered}
\frac{A m_{1\left(\mathrm{CH}_{3}\right)}}{A_{\text {total }}}=\frac{n_{1} m_{1}}{\left(a_{1} m_{1}+b_{2} m_{2}\right)}, \\
A m_{2(\mathrm{CH})}=A_{\text {total }}=\frac{n_{2} m_{2}}{\left(a_{1} m_{1}+b_{2} m_{2}\right)},
\end{gathered}
$$

where $A m_{1}$ and $A m_{2}$ are the normalized areas per $H$ from the corresponding functional groups of the monomer unit regions in ${ }^{1} \mathrm{H}$ NMR spectra; $A_{\text {total }}$ is the total area of protons in the copolymer; $n_{1}$ and $n_{2}$ are the integers of proton(s) in the functional group of the monomers; $a$ and $b$ are the integers of protons in the monomer units $\left(m_{1}\right.$ and $\left.m_{2}\right)$; in the case of $\left(m_{1}+m_{2}\right)=1$, monomer unit ratios can be calculated from (2) using the following simplified form:

$$
\frac{m_{1}}{m_{2}}=f=\frac{n_{2} A m_{1\left(\mathrm{CH}_{3}\right)}}{n_{1} A m_{2\left(\mathrm{CH} \text { or } \mathrm{CH}_{3}\right)}} .
$$

The CHNS-932 Model LECO Elemental Analyzer was used for the determination of $\mathrm{C}, \mathrm{H}$, and $\mathrm{N}$ contents in the copolymers synthesized. Molar fractions (mol\%) of comonomer units $\left(m_{1}\right.$ and $\left.m_{2}\right)$ in NTBA-MA copolymers using elemental analysis data (content of $\mathrm{N}$ ) were calculated according to the following equation:

$$
m_{1}=\frac{M_{2}}{\left[\left(A_{\mathrm{N}} / B\right)-\Delta M \times 10^{-2}\right]},
$$

where $M_{2}$ is the molecular weight of MA units; $A_{\mathrm{N}}$ is the atom weight of $\mathrm{N} ; B$ is the content of $\mathrm{N}$ in the copolymers (\%); $\Delta M=M_{1}-M_{2}\left(M_{1}\right.$ is the molecular weight of the NTBA unit).

Fourier transform infrared spectroscopy, FTIR, (Perkin Elmer 100 spectrometer) was used to determine the copolymer composition using either solid films or mull samples in the $4000-600 \mathrm{~cm}^{-1}$ range, where 30 scans were taken at $4 \mathrm{~cm}^{-1}$ resolution. The mulls were prepared by mixing the polymer with dry $\mathrm{KBr}$ powder and pressing into a transparent $\mathrm{KBr}$ pellet. Solid films were prepared by solution casting the polymer onto a $\mathrm{KBr}$ pellet followed by evaporation of the solvent.

${ }^{1} \mathrm{H}$ NMR spectra were recorded on a Varian $400 \mathrm{NMR}$ spectrometer with DMSO- $d_{6}$ as a solvent at $50^{\circ} \mathrm{C}$. Samples for ${ }^{1} \mathrm{H}$ NMR spectroscopy were prepared by dissolving about $30 \mathrm{mg}$ of products in $1 \mathrm{~mL}$ dimethyl sulfoxide- $d_{6}$. Tetramethylsilane was used as an internal reference.

The molecular weights $\left(M_{n}\right.$ and $\left.M_{w}\right)$ and the dispersity index $\left(M_{w} / M_{n}\right)$ of the copolymers were determined by Gel-Permeation Chromatography using a Shimpack 804 column with THF as a mobile phase-eluent at a flow rate of $1.0 \mathrm{~mL} / \mathrm{min}$ at $35^{\circ} \mathrm{C}$. Standard polystyrene was used for molecular weight calibration.

Acid numbers (AN) of the anhydride-containing copolymers were determined by standard titration method [29, 30]:

$$
\begin{gathered}
\mathrm{AN}\left(\frac{\mathrm{mg} \mathrm{KOH}}{\mathrm{g}}\right)=\frac{\mathrm{ml} \mathrm{KOH} \times \mathrm{N} \mathrm{KOH} \times 56.11}{\mathrm{~g} \text { polymer }}, \\
\mathrm{MA}(\%)=\frac{\mathrm{AN} \times 98}{2 \times 561} .
\end{gathered}
$$

The unit viscosity factor was determined by viscosimetric method. For viscosimetric characterization, solutions of all samples in THF, with a molarity of $0.1-1.0 \mathrm{~g} / \mathrm{dL}$, were prepared. The time flow of the solutions and solvents was recorded by Ubbelohde type viscosimeter placed in a thermostatic water bath at $25 \pm 0.1^{\circ} \mathrm{C}$. Specific viscosity $\left(\eta_{\mathrm{sp}}\right)$ and relative viscosity $\left(n_{r}\right)$ were calculated $((6)$ and $(7))$. By using these values with Solomon-Ciuta equation (8), intrinsic viscosity $[\eta]$ was calculated:

$$
n_{r}=\frac{t}{t_{o}}
$$

where $t_{o}$ is flow time of solvent, $t$ is flow time of solution:

$$
\begin{gathered}
\eta_{\mathrm{sp}}=\eta_{r}-1 \\
{[\eta]=\frac{1.414}{C}\left(\eta_{\mathrm{sp}}-\ln \eta_{r}\right)^{1 / 2},}
\end{gathered}
$$

where $[\eta]$ is intrinsic viscosity, $C$ is the molarity of the solution.

\section{Results and Discussion}

3.1. Synthesis of the NTBA-MA Copolymer. The synthesis of the copolymer of NTBA and MA was carried out in both four steps and in one step adding NTBA using AIBN as an initiator at $65^{\circ} \mathrm{C}$ in a different monomer ratio (NTBA/MA). In the four steps of polymerization, the dosing of the more reactive monomer NTBA was regulated to obtain copolymers of controlled composition. The monomer NTBA was introduced in four equal doses over a time period of 2 hours and 15 minutes at the beginning of the reaction. The copolymer composition and nitrogen content are given in Table 1. The polymerization reaction is shown in Scheme 1.

The effects of various parameters such as the feed mol ratio (NTBA/MA), amount of AIBN, reaction temperature, and reaction time were determined. Also, Table 2 gives the intrinsic viscosities $[\eta]$, molecular weights $\left(M_{n}\right)$, polydispersity index (PDI), conversion, and acid numbers (AN) for the NTBA-MA copolymer. Adding four steps to the reaction medium of NTBA gave better results than adding one step (Table 2). 
TABLE 1: ${ }^{1} \mathrm{H}$ NMR, FTIR, and elemental analysis of NTBA/MA copolymers synthesized from various monomers feed ratio.

\begin{tabular}{|c|c|c|c|c|c|c|c|c|c|c|}
\hline \multirow{3}{*}{$\begin{array}{l}\text { Feed mol ratio } \\
\text { NTBA/MA }\end{array}$} & \multirow{3}{*}{$\begin{array}{c}A m_{1} \\
(\mathrm{NTBA})^{\mathrm{a}}\end{array}$} & \multirow{3}{*}{$\begin{array}{c}A m_{2} \\
(\mathrm{MA})^{\mathrm{a}}\end{array}$} & \multirow{3}{*}{$\begin{array}{c}\Delta A_{1}^{\mathrm{b}} \\
1658 \mathrm{~cm}^{-1} \\
\text { integral area } \\
A m_{1(\mathrm{NTBA})}\end{array}$} & \multirow{3}{*}{$\begin{array}{c}\Delta A_{2}^{\mathrm{b}} \\
1775 \mathrm{~cm}^{-1} \\
\text { integral area } \\
A m_{2(\mathrm{MA})}\end{array}$} & \multicolumn{4}{|c|}{ Copolymer composition (mol\%) } & \multicolumn{2}{|c|}{ FTIR analysis } \\
\hline & & & & & \multicolumn{2}{|c|}{${ }^{1} \mathrm{H}$ NMR analysis } & \multicolumn{2}{|c|}{ Nitrogen analysis } & \multirow[b]{2}{*}{$m_{1}$} & \multirow[b]{2}{*}{$m_{2}$} \\
\hline & & & & & $m_{1}$ & $m_{2}$ & $m_{1}$ & $m_{2}$ & & \\
\hline $70 / 30$ & 0.065 & 0.054 & 0.510 & 0.280 & 66.5 & 33.5 & 65.8 & 34.2 & 66.1 & 33.9 \\
\hline $60 / 40$ & 0.048 & 0.042 & 0.468 & 0.312 & 58.4 & 41.6 & 60.8 & 39.2 & 59.2 & 40.8 \\
\hline $50 / 50$ & 0.056 & 0.047 & 0.487 & 0.455 & 55.1 & 44.9 & 54.5 & 45.5 & 54.1 & 45.9 \\
\hline $40 / 60$ & 0.034 & 0.030 & 0.405 & 0.587 & 50.2 & 49.8 & 48.8 & 51.2 & 48.7 & 51.3 \\
\hline $30 / 70$ & 0.023 & 0.024 & 0.355 & 0.865 & 47.6 & 52.4 & 46.6 & 53.4 & 46.8 & 53.2 \\
\hline
\end{tabular}

${ }^{a}$ Integral area for $\mathrm{CH}$ chemical shift of NTBA (terbutyl group) and MA anhydride (methyne group) units.

${ }^{\mathrm{b}}$ The values of $\Delta A_{1}=0.178$ and $\Delta A_{2}=0.275$ for poly (NTBA) and poly (MA), respectively; $1365 \mathrm{~cm}^{-1}$ is used as a less changed standard band.

TABLE 2: The effect on copolymerization of reaction conditions.

\begin{tabular}{|c|c|c|c|c|c|c|c|c|c|c|}
\hline Run & $\begin{array}{c}\text { Feed mol ratio } \\
\text { NTBA/MA }\end{array}$ & $\begin{array}{c}\text { AIBN } \\
(\% \mathrm{~mol})\end{array}$ & $\begin{array}{c}\text { Temperature } \\
\left({ }^{\circ} \mathrm{C}\right)\end{array}$ & $\begin{array}{l}\text { Time } \\
\text { (h) }\end{array}$ & $\begin{array}{c}M_{n} \\
(\mathrm{~g} / \mathrm{mol})\end{array}$ & $\eta(\mathrm{g} / \mathrm{dL})$ & PDI & $\begin{array}{c}\text { Acid number } \\
(\mathrm{mg} \mathrm{KOH} / \mathrm{g})\end{array}$ & $\begin{array}{c}\mathrm{N} \\
\text { content } \\
(\%)\end{array}$ & $\begin{array}{c}\text { Conversion } \\
(\%)\end{array}$ \\
\hline $1^{\mathrm{a}}$ & $70 / 30$ & 1.0 & 65 & 24 & 2800 & 0.063 & 1.09 & 285 & 8.54 & 3.3 \\
\hline $2^{\mathrm{a}}$ & $60 / 40$ & 1.0 & 65 & 24 & 3100 & 0.069 & 1.10 & 305 & 8.01 & 4.9 \\
\hline $3^{\mathrm{a}}$ & $50 / 50$ & 1.0 & 65 & 24 & 3400 & 0.073 & 1.10 & 354 & 7.46 & 9.1 \\
\hline $4^{\mathrm{a}}$ & $40 / 60$ & 1.0 & 65 & 24 & 4000 & 0.081 & 1.11 & 378 & 6.87 & 14.6 \\
\hline $5^{\mathrm{a}}$ & $30 / 70$ & 1.0 & 65 & 24 & 6100 & 0.097 & 1.12 & 412 & 6.52 & 34.1 \\
\hline $6^{\mathrm{a}}$ & $30 / 70$ & 0.3 & 65 & 24 & 6300 & 0.098 & 1.15 & 381 & 0.76 & 4.3 \\
\hline $7^{\mathrm{a}}$ & $30 / 70$ & 0.7 & 65 & 24 & 6200 & 0.096 & 1.13 & 390 & 1.54 & 8.6 \\
\hline $8^{\mathrm{a}}$ & $30 / 70$ & 1.4 & 65 & 24 & 5000 & 0.092 & 1.12 & 378 & 6.85 & 38.8 \\
\hline $9^{\mathrm{a}}$ & $30 / 70$ & 1.0 & 65 & 6 & 4800 & 0.091 & 1.11 & 362 & 2.69 & 15.1 \\
\hline $10^{\mathrm{a}}$ & $30 / 70$ & 1.0 & 65 & 3 & 4500 & 0.087 & 1.12 & 344 & 1.47 & 8.3 \\
\hline $11^{\mathrm{a}}$ & $30 / 70$ & 1.0 & 80 & 24 & 6000 & 0.096 & 1.16 & 384 & 6.03 & 34.0 \\
\hline $12^{\mathrm{a}}$ & $30 / 70$ & 1.0 & 50 & 24 & 4800 & 0.092 & 1.11 & 372 & 3.56 & 20.8 \\
\hline $13^{\mathrm{b}}$ & $30 / 70$ & 1.0 & 65 & 3 & 4200 & 0.083 & 1.11 & 322 & 1.23 & 7.2 \\
\hline $14^{\mathrm{b}}$ & $30 / 70$ & 1.0 & 65 & 24 & 5900 & 0.095 & 1.11 & 378 & 4.17 & 24.4 \\
\hline
\end{tabular}

${ }^{\mathrm{a}} \mathrm{NTBA}$ added in four portions. ${ }^{\mathrm{b}} \mathrm{NTBA}$ added at once.

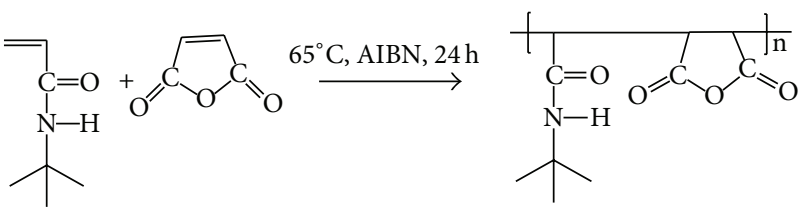

Scheme 1: Polymerization reaction of NTBA-MA.

3.2. H-Bonding Effect in Radical Copolymerization. Hbonding as a variety of intermolecular interaction exertion essentially influenced the kinetic and elementary actions of radical polymerization [13]. H-bond is formed due to both electrostatic [31] and donor-acceptor interactions in $\mathrm{H}$ complexes [32]. Despite that, considerable contribution of an electrostatic interaction to energy of $\mathrm{H}$-bond role of charge transfer (donor-acceptor interaction), which is reasonable for change of electron state and reactivity of individual components of monomer H-complex system, is highly essential [21].
These directional interactions can be expressed as $-\mathrm{X}$...H, -Y...H $(\mathrm{X}, \mathrm{Y}=\mathrm{N}, \mathrm{O}, \ldots)$ stable and dynamic molecular complexes can be prepared by simple molecular self-assembly processes using nucleic acids, proteins, and polysaccharides having hydrogen bonding groups, which participate in the formation of supramolecular structures and the induction of function [21]. In these system, anomaly high shifts and broad of H-bond in IR spectra and its high chemical shifts of the proton in NMR spectra were observed [21]. The thermodynamic peculiarities of H-complex formation in the monomer-monomer and monomer-solvent systems were described by Kabanov et al. [9]. The determination of selfassociation and interassociation equilibrium constants of $\mathrm{H}$ bond formation has been discussed in detail by Coleman and Painter [33], according to the authors, H-bonds are continually breaking and reforming under the influence of thermal motion, and at any instant there is a distribution of species consisting of free monomers (non-hydrogenbonded), hydrogen bonded dimers, and hydrogen bonded 


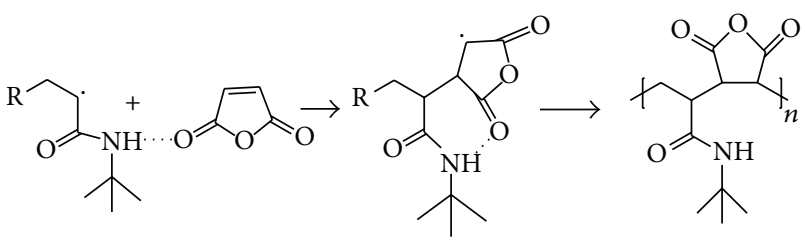

SCHeme 2: The effect of H-bonding on copolymerization.

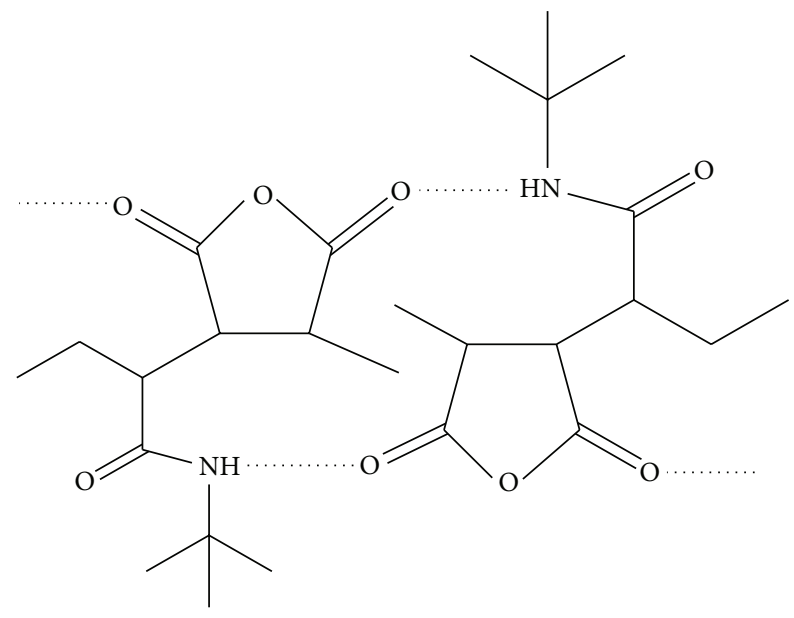

SCHEME 3

multimers. This distribution is affected by changes in temperature and concentration. The effect of $\mathrm{H}$-complex in radical alternating copolymerization of MA and fumaric acid (FA) with acrylic acid (AA) was observed by El'Saied et al. [34]. They showed that copolymerization of these monomer pairs proceeds through formation of MA...AA and FA...AA Hcomplexes $(-\mathrm{C}=\mathrm{O} . . \mathrm{HO}-)$ and it is possible to direct up processes away from the formation of alternating copolymers to the formation of random copolymers with different compositions by using naphthalene as an electron donor substance that forms a donor-acceptor complex with a double bond of acceptor MA. In this study, when examining the nature of the conjugation between functional groups and double bonds ( $\mathrm{C}=\mathrm{O}$ of amide and anhydride), NTBA and MA monomers can be considered electron acceptors. However, this does not prevent the monomers from having sufficient activity in free-radical copolymerization of NTBA-MA monomer pairs thanks to the interaction between functional groups of the comonomers or macroradicals through H-bonding [11, 12, 26]. This effect can be illustrated as is shown in Schemes 2 and 3.

Copolymerizations were carried out to low conversions $(\leq 10 \%)$ in order to determine monomer reactivity ratios in the steady-state kinetics by using the known terminal model of the Kelen-Tüdös (KT) equation [35]:

$$
\eta=\left(\frac{r_{1}+r_{2}}{\alpha}\right) \xi-\frac{r_{2}}{\alpha}
$$

where $\eta=[F(f-1) / f] /\left(F^{2} / f+\alpha\right) ; \xi=\left(F^{2} / f\right) /\left(F^{2} / f+\right.$ $\alpha) ; \alpha$ (arbitrary constant) $=\left(F^{2} / f\right)_{\min }\left(F^{2} / f\right)_{\max } ; F=$ [NTBA] $/[\mathrm{MA}]$; and $f=\left(m_{1} / m_{2}\right)$.

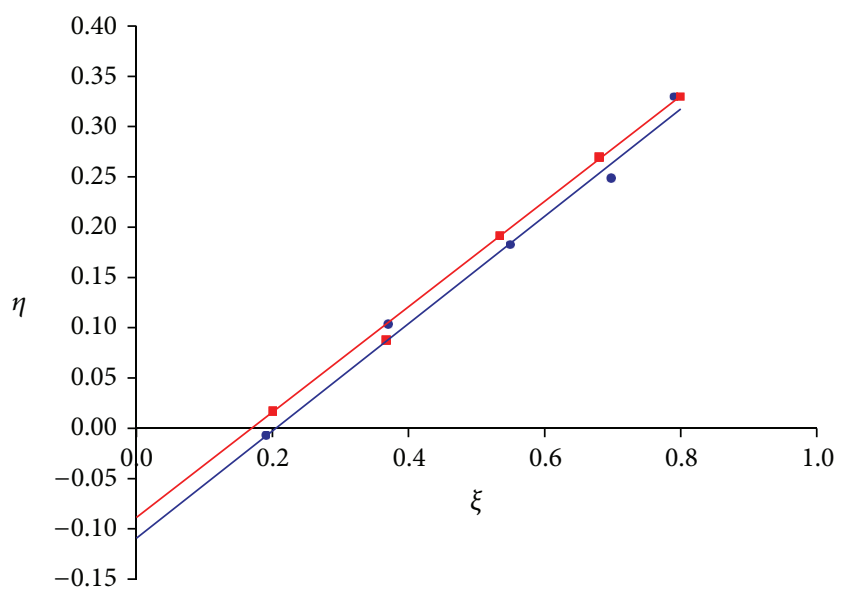

FIGURE 1: KT plots for the copolymerization of NTBA-MA using - ${ }^{1} \mathrm{H}$ NMR and - elemental analysis data. Slope $=r_{1}+r_{2} / \alpha$ and intercept $-r_{2} / \alpha$.

Results of FTIR analysis of copolymers prepared using different monomer feed ratios are illustrated in Figure 3. On the basis of these data, the values of absorption bands for the comonomers units are calculated and are used for the determination of copolymer composition according to (1).

The results of ${ }^{1} \mathrm{H}$ NMR and elemental analysis of various initial monomer ratios of copolymer are illustrated in Figure 4 and summarized in Table 1. Copolymer compositions calculated using elemental analysis data (contents of $\mathrm{N}$ were in very good agreement with those obtained from ${ }^{1} \mathrm{H}$ NMR analysis using (3) and (4). For comparison, a nonlinear regression (NLR) procedure using a microcomputer program [36] has also been applied to recalculate copolymerization constants. Table 3 shows that the copolymerization of monomers in NTBA-MA system has a tendency toward alternation, especially at NTBA $\leq 50 \mathrm{~mol} \%$.

3.3. Structural Analysis of the NTBA-MA Copolymer. An elemental analysis determined the carbon, hydrogen, and nitrogen content of the NTBA-MA copolymer. The polymerization ratio of the monomer and the content of the amine group in the copolymer were calculated from the carbon and nitrogen content of the copolymer. The results shown in Table 1 indicate that the amine group content in the copolymer slightly increased the monomer molar ratio in the copolymer and greatly increased with the growth of the monomer ratio NTBA/MA. The effect of the monomer ratio on the growth of the amine group content due to the probability of the NTBA self-polymerization increased with enlargement of the monomer ratio NTBA/MA.

Tables 1 and 2 indicate that the molecular weight of the NTBA-MA copolymer depended on the monomer ratio NTBA/MA and the molecular weight of the NTBA-MA copolymer greatly increased with the decrease of the monomer ratio NTBA/MA (up to NTBA/MA; 30/70). The results indicate that a significant change in the amount of conversion and molecular weight has been observed with increasing the amount of MA (Table 2). For the system of the NTBA-MA 
TABLE 3: Kelen-Tüdös (KT) parameters for determination of monomer reactivity ratios for NTBA-MA pair.

\begin{tabular}{lccccccccccc}
\hline $\begin{array}{l}\text { Monomer ratio } \\
\text { NTBA/MA }\end{array}$ & \multirow{2}{*}{ By $^{1} \mathrm{H}$ NMR } & \multicolumn{2}{c}{ Parameters of KT equation } & \multicolumn{2}{c}{ By N analysis } & \multicolumn{2}{c}{ Parameters of KT equation } & \multicolumn{2}{c}{ Mean sequence length $^{\mathrm{a}}$} \\
$F$ & $f$ & $F^{2} / f+\alpha^{\mathrm{b}}$ & $\eta$ & $\xi$ & $f$ & $F^{2} / f+\alpha^{\mathrm{b}}$ & $\eta$ & $\xi$ & $\mu_{1}$ & $\mu_{2}$ \\
\hline 2.35 & 2.11 & 3.36 & 0.33 & 0.79 & 2.05 & 3.42 & 0.33 & 0.80 & 1.91 & 1.04 \\
1.53 & 1.43 & 2.30 & 0.24 & 0.70 & 1.51 & 2.10 & 0.27 & 0.68 & 1.70 & 1.05 \\
1.00 & 1.30 & 1.42 & 0.18 & 0.55 & 1.40 & 1.43 & 0.19 & 0.52 & 1.64 & 1.05 \\
0.66 & 1.12 & 1.08 & 0.10 & 0.37 & 1.13 & 1.10 & 0.08 & 0.35 & 1.51 & 1.06 \\
0.40 & 0.94 & 0.91 & -0.01 & 0.18 & 1.00 & 0.90 & 0.02 & 0.20 & 1.44 & 1.07 \\
\hline
\end{tabular}

Rection conditions: solvent: $p$-dioxane, $[M]$ total $=1.33 \mathrm{~mol} / \mathrm{L},[\mathrm{AIBN}]=6.6 \times 10^{-4} \mathrm{~mol} / \mathrm{L}, 65 \pm 0.1^{\circ} \mathrm{C}$, conversion $\leq 10 \%$.

${ }^{a}$ These values were calculated by using the following $r_{1}$ and $r_{2}$ values: 0.44 and 0.07 for NTBA-MA pair.

${ }^{\mathrm{b}} \alpha$ (arbitrary constant $)=0.68$ by elemental analysis.

TABLE 4: The values copolymerization $\left(r_{1}\right.$ and $\left.r_{2}\right)$ for NTBA $\left(M_{1}\right)$ MA $\left(M_{2}\right)$ monomer pair determining by KT and NLR methods using ${ }^{1} \mathrm{H}$ NMR and elemental analysis techniques.

\begin{tabular}{lccc}
\hline Copolymer & Methods & $r_{1}$ & $r_{2}$ \\
\hline NTBA-MA & ${ }^{1}$ H NMR analysis (KT) & 0.43 & 0.11 \\
NTBA-MA & NLR & 0.45 & 0.13 \\
NTBA-MA & Elemental analysis (KT) & 0.46 & 0.07 \\
NTBA-MA & NLR & 0.46 & 0.068 \\
\hline
\end{tabular}

copolymerization, the NTBA and MA easily copolymerized, but the self-polymerization of NTBA is easier than the copolymerization of NTBA-MA, and the self-polymerization of MA happens with difficultly.

As shown in Table 2, the optimum reaction conditions are as follows: feed mol ratio NTBA/MA is $30 / 70(\mathrm{~mol} / \mathrm{mol})$, the amount of AIBN is $1 \% \mathrm{~mol}$, at $65^{\circ} \mathrm{C}$ of temperature, and 24 hours of time under reflux. A considerable increase in conversion was observed when increasing the amount of AIBN initiator. However, the results indicate that a lower amount of initiator, which depends on the amount of AIBN, is desired to promote the molecular weight. Under optimum reaction conditions, acid number is increased to $412 \mathrm{mg}$ $\mathrm{KOH} / \mathrm{g}$ (Run 5, Table 2). Lowering the reaction temperature decreased the copolymerization conversion and molecular weight. Likewise, lowering the reaction time significantly decreased the copolymerization conversion and molecular weight. Adding four steps to the reaction medium of NTBA, the more reactive monomer, gave better results than adding one step. In the same reaction conditions, conversion is increased from $24.4 \%$ to $34.1 \%$, and likewise, molecular weight is increased from $5900 \mathrm{~g} / \mathrm{mol}$ to $6100 \mathrm{~g} / \mathrm{mol}$. (Runs 5 and 14, Table 2). Under optimum reaction conditions, elemental analysis, acid numbers, and GPC results were determined as molecular weight of $6100 \mathrm{~g} / \mathrm{mol}$ and conversion, $34.1 \%$.

Monomer reactivity ratios $\left(r_{1}\right.$ and $\left.r_{2}\right)$ were evaluated using experimental data, presented in Tables 1 and 3 , from KT plots of $\xi$ versus $\eta$ (Figure 1) and NLR analysis. As evidenced from the values, which are summarized in Table 4 , alternating copolymerizations are realized in monomer systems with a highly visibly degree of alternation of monomer units in the
NTBA-MA system. Copolymerization constants determined by KT method and calculated by NLR method have similar values indicating good agreement between both FTIR and ${ }^{1} \mathrm{H}$ NMR analysis techniques (Tables 3 and 4). As an additional conformation of the alternating tendency of the monomers in the systems studied, the monomer sequence lengths ( $\mu_{1}$ and $\mu_{2}$ ) are calculated from well-known equations [37]:

$$
\begin{aligned}
& \mu_{1}=1+r_{1}\left(\frac{m_{1}}{m_{2}}\right), \\
& \mu_{2}=1+r_{2}\left(\frac{m_{2}}{m_{1}}\right) .
\end{aligned}
$$

Table 3 presents the values of $\mu_{1}$ and $\mu_{2}$. As seen from the values for different monomer-copolymer compositions, the value of $\mu_{1}$ (NTBA unit sequence length) visibly changes from 1.44 to 1.91 in the NTBA-MA systems in increasing NTBA feed concentration. Meanwhile, the mean unit sequence lengths for MA anhydride units $\left(\mu_{2}\right)$ have relatively low and nearly unchanged values. This fact is correlated with the low values of $r_{2}$ and confirms the alternating tendency of the copolymer (Table 4 ).

In general, these results allow us to assume that the chain growth reactions proceed predominantly by the addition of anhydride comonomers to $\sim \mathrm{NTBA}^{\circ}$ macroradical through the intermediate formation of an $\mathrm{H}$-bond between secondary amide and anhydride carbonyl groups according to Scheme 2.

The parameters of specific activity $\left(Q_{1}\right)$ and polarity $\left(e_{1}\right)$ for the NTBA monomer were calculated using the $Q-e$ value reported by Alfrey and Price [38] in the form of the following equations:

$$
\begin{gathered}
e_{2}=e_{1} \pm\left(-\ln r_{1} r_{2}\right), \\
Q_{1}=\left(\frac{Q_{2}}{r_{2}}\right) \exp \left[-e_{1}\left(e_{1}-e_{2}\right)\right] .
\end{gathered}
$$

Using the known values of $Q_{2}=0.23$ and $e_{2}=2.25$ for the MA comonomer [39], the parameters of $Q_{1}=0.28$ and $e_{1}=-0.69$ have been calculated for NTBA, which describe the energy of localization, order, and $\pi$-electron density of the NTBA double bond. 


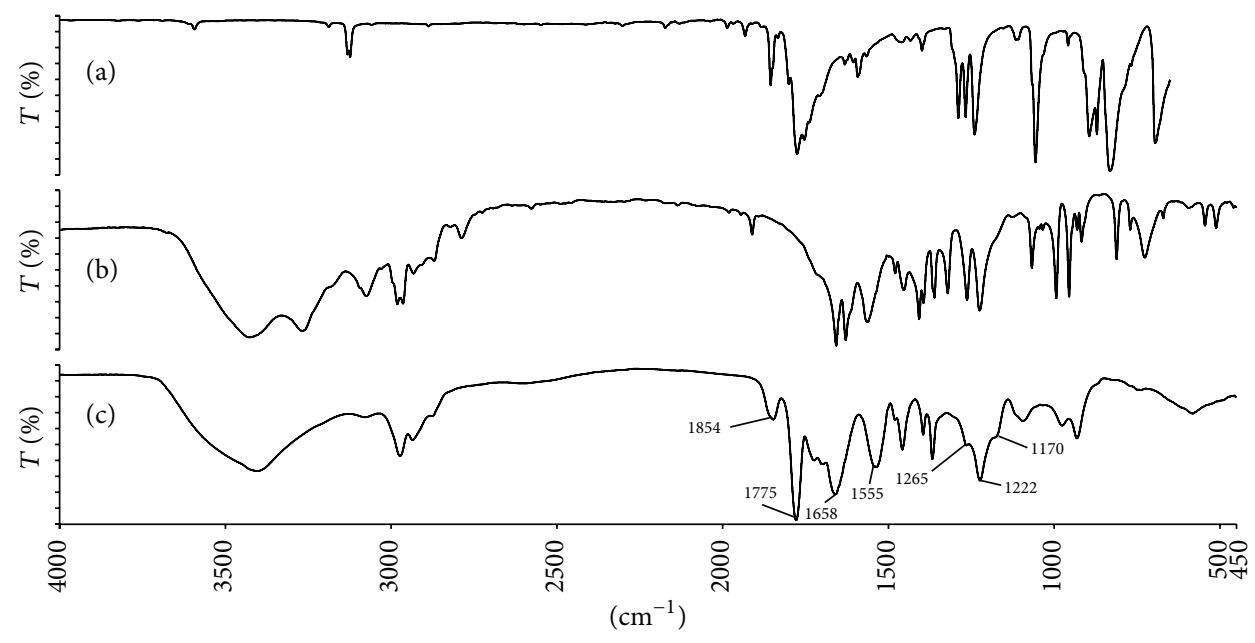

Figure 2: Fragments of FTIR spectra of the MA (a), NTBA (b), and poly(NTBA-co-MA) (c).

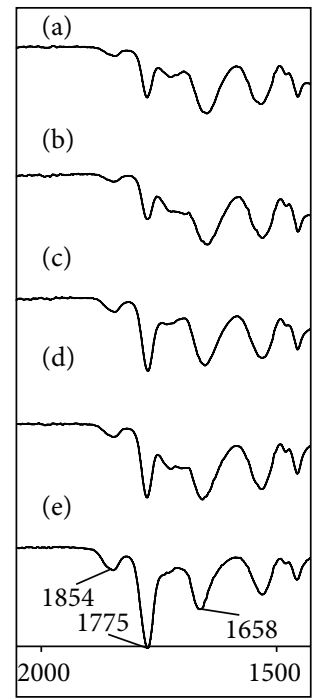

FIGURE 3: FTIR spectra of the poly(NTBA-co-MA)s preparing in different monomer feed. NTBA : MA; $70: 30$ (a), $60: 40$ (b), 50:50 (c), $40: 60(\mathrm{~d})$, and $30: 70$ (e).

3.3.1. FT-IR Analysis. Figure 2 shows the FTIR spectra of MA, NTBA, and Poly(NTBA-MA). The NTBA-MA copolymer spectra display the characteristic absorption bands at $1658 \mathrm{~cm}^{-1}$ ( $n \mathrm{C}=\mathrm{O}$, amide $\mathrm{I}$ ), at $1555 \mathrm{~cm}^{-1}$ ( $\mathrm{N}-\mathrm{H}$ bending, amide II), at about $1265 \mathrm{~cm}^{-1}$ (trans-amide III), 3400$3100 \mathrm{~cm}^{-1}$ broad band for $\mathrm{NH}$ secondary amide and the band could be assigned to $\mathrm{H}$-bonded $\mathrm{NH}$, mainly to the $\mathrm{C}=\mathrm{O}$ of the MA unit. The band assigned to the tertiary butyl groups $\left[-\mathrm{C}\left(\mathrm{CH}_{3}\right)_{3}\right]$ at $1222 \mathrm{~cm}^{-1}$ [40-42]. The absorption region between 2860 and $2973 \mathrm{~cm}^{-1}$ corresponds to $-\mathrm{CH}$ stretching vibrations of $-\mathrm{CH}_{3}$ and $-\mathrm{CH}_{2}$-groups $[43,44]$. The MA spectra display characteristic absorption bands at 1854$1775 \mathrm{~cm}^{-1}$ corresponding to $\mathrm{C}=\mathrm{O}$ stretching of anhydride group and $1170 \mathrm{~cm}^{-1}$ broad C-O-C anhydride [11].
It can be proposed that intermolecular $\mathrm{H}$-bonded fragments are most probably formed between alternating NTBAMA diads of macromolecules as follows.

Figure 3 illustrates the structure composition relationship for NTBA-MA copolymer.

An increase in the quantity of MA in the NTBA-MA copolymers was observed. An increased intensity of the peaks at $1854-1775 \mathrm{~cm}^{-1}$ corresponds to $\mathrm{C}=\mathrm{O}$ stretching of anhydride group. Also, the increasing quantity NTBA was observed in the increased intensity of the peaks at $1658 \mathrm{~cm}^{-1}$ corresponding to $\mathrm{C}=\mathrm{O}$ amide I (Figure 3 ).

3.3.2. ${ }^{1} H$ NMR Analysis. Supporting evidence for the structural elucidation is revealed by ${ }^{1} \mathrm{H}$ NMR analysis. Characteristic peaks $\left({ }^{1} \mathrm{H}\right.$ NMR spectra (in DMSO- $d_{6}$ at $50^{\circ} \mathrm{C}$ ), ppm: (1) $9 \mathrm{H}, \mathrm{CH}_{3} 1.3$, (2) $2 \mathrm{H}, \mathrm{CH}_{2} 1.6$, (3) $1 \mathrm{H}, \mathrm{CH} 2.4,(5) 1 \mathrm{H}, \mathrm{NH}$ 7.8 for NTPA unit; (4) $2 \mathrm{H}, \mathrm{CH} 3.5$ for maleic unit in Figure 4) can be identified in the ${ }^{1} \mathrm{H}$ NMR spectra of the copolymer and used as analytical signals for quantitative analysis of polymer composition. Figure 4 shows the ${ }^{1} \mathrm{H}$ NMR spectra of NTBAMA copolymer, and Figure 5 shows the ${ }^{1} \mathrm{H}$ NMR spectra of PolyNTBA.

\section{Conclusion}

Poly(NTBA-co-MA)s are synthesized by the radical copolymerization method in the chosen conditions, which are considered in Section 2. The compositions of prepared copolymers using a wide range of monomer feed were determined by the elemental nitrogen analysis of NTBA monomer units containing $\mathrm{N}$ atoms. In addition, this study used the Fourier transform infrared (FTIR) and ${ }^{1} \mathrm{H}$ NMR analysis methods to evaluate some structural peculiarities of synthesized copolymers and determine copolymer compositions. The relatively high activity of the pair monomers studied having a tendency toward alternating copolymerization was explained by the effect of $\mathrm{H}$-bond formation between $\mathrm{C}=\mathrm{O}$ 


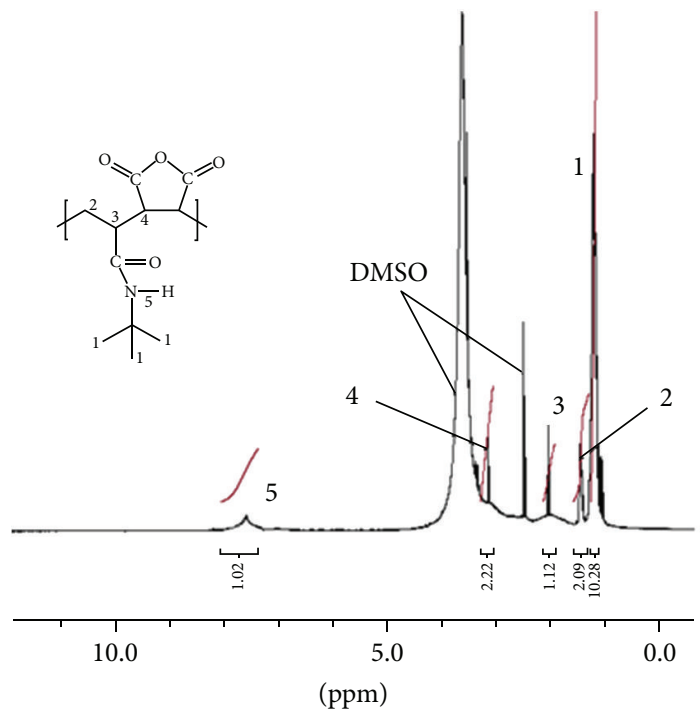

Figure $4:{ }^{1} \mathrm{H}$ NMR spectra of poly(NTBA-co-MA) in DMSO- $d_{6}$ at $50^{\circ} \mathrm{C}$.

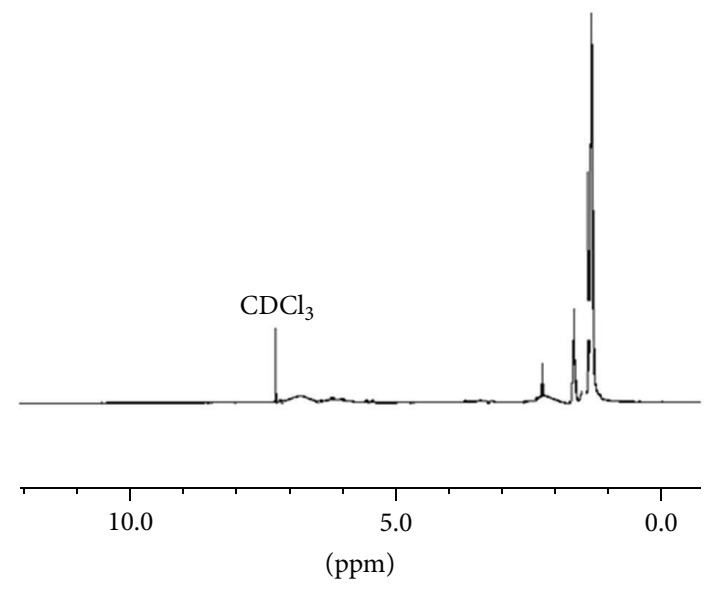

FIGURE 5: ${ }^{1} \mathrm{H}$ NMR spectra of poly-NTBA in $\mathrm{CDCl}_{3}$ at $27^{\circ} \mathrm{C}$.

(anhydride) and $\mathrm{NH}$ (amide) groups during chain growth reactions. The formation of alternating copolymers, predominantly at $\leq 50 \mathrm{~mol} \%$ of NTBA in the monomer feed, was confirmed by the results of copolymer compositionproperty relationship studies. Synthesized and characterized new amphiphilic copolymers can be used as macromolecular drug carries and advanced applications in biotechnology.

\section{Acknowledgment}

The authors thank Selcuk University Research Project Fund (SUBAP 12201027) for support of this work.

\section{References}

[1] D. A. Tirrell, M. H. Tirrell, N. M. Bikalws et al., Encyclopedia of Polymers Sciences and Engineering, vol. 4, John Wiley \& Sons, New York, NY, USA, 1985.
[2] A. Gallardo, A. R. Lemus, J. San Román, A. Cifuentes, and J.-C. Díez-Masa, "Micellar electrokinetic chromatography applied to copolymer systems with heterogeneous distribution," Macromolecules, vol. 32, no. 3, pp. 610-617, 1999.

[3] O. Vogl, A. C. Albertsson, and Z. Janovic, "New developments in speciality polymers: polymeric stabilizers," Polymer, vol. 26, no. 9, pp. 1288-1296, 1985.

[4] J. M. G. Cowie, Alternating Copolymers, Plenum Press, New York, NY, USA, 1985.

[5] D. J. T. Hill, J. H. O’Donnell, and P. W. O'Sullivan, "Analysis of the mechanism of copolymerization of styrene and maleic anhydride," Macromolecules, vol. 18, pp. 9-17, 1985.

[6] B. Klumperman, "Mechanistic considerations on styrenemaleic anhydride copolymerization reactions," Polymer Chemistry, vol. 1, no. 5, pp. 558-562, 2010.

[7] E. Tsuchida and T. Tomono, "Mechanism of alternating copolymerization of styrene and maleic anhydride," Macromolocular Chemistry, vol. 141, pp. 265-298, 1971.

[8] Z. M. O. Rzaev, Polymers and Copolymers of Maleic Anhydride, vol. 102 of Chemical Abstracts, Elm, Baku, Azerbaijan, 1985.

[9] V. A. Kabanov, V. P. Zubov, and Y. Semchikov, Complex Radical Polymerization, Khimiya, Moscow, Russia, 1987.

[10] Z. M. O. Rzaev, "Complex-radical alternating copolymerization," Progress in Polymer Science, vol. 25, no. 2, pp. 163-217, 2000.

[11] S. Dinçer, V. Köseli, H. Kesim, Z. M. O. Rzaev, and E. Pişkin, "Radical copolymerization of $\mathrm{N}$-isopropylacrylamide with anhydrides of maleic and citraconic acids," European Polymer Journal, vol. 38, no. 11, pp. 2143-2152, 2002.

[12] S. Dincer, Z. M. O. Rzaev, and E. Piskin, "Synthesis and characterization of stimuli-responsive poly $(\mathrm{N}$-isopropylacrylamideco-N-vinyl-2-pyrrolidone)," Journal of Polymer Research, vol. 13, no. 2, pp. 121-131, 2006.

[13] H. K. Can, Z. M. O. Rzaev, and A. Güner, "H-bonding effect in radical terpolymerization of maleic anhydride, acrylic acid (methyl acrylate) and vinyl acetate," Hacettepe Journal of Biology and Chemistry, vol. 40, pp. 427-443, 2012.

[14] B. C. Trivedi and B. M. Culbertson, Maleic Anhydride, Plenum Press, New York, NY, USA, 1982.

[15] H. Ringsdorf, J. Venzmer, and F. M. Winnik, "Fluorescence studies of hydrophobically modified poly(N-isopropylacrylamides)," Macromolecules, vol. 24, no. 7, pp. 1678-1686, 1991.

[16] J.-P. Chen and M.-S. Hsu, "Preparations and properties of temperature-sensitive poly( $\mathrm{N}$-isopropylacrylamide)-chymotrypsin conjugates," Journal of Molecular Catalysis B, vol. 2, no. 4-5, pp. 233-241, 1997.

[17] C. K. Chee, S. Rimmer, I. Soutar, and L. Swanson, "Timeresolved fluorescence anisotropy studies of the temperatureinduced intramolecular conformational transition of poly $(\mathrm{N}$ isopropylacrylamide) in dilute aqueous solution," Polymer, vol. 38, no. 2, pp. 483-486, 1997.

[18] H. G. Schild and D. A. Tirrell, "Use of nonradiative energy transfer to explore interpolymer and polymer-solute interactions in aqueous solutions of poly(N-isopropylacrylamide)," Macromolecules, vol. 25, no. 18, pp. 4553-4558, 1992.

[19] A. Reiche, A. Weinkauf, B. Sandner, F. Rittig, and G. Fleischer, "Alternating copolymers for novel polymer electrolytes: the electrochemical properties," Electrochimica Acta, vol. 45, no. 8, pp. 1327-1334, 2000.

[20] T. Kato, N. Mizoshita, and K. Kanie, "hydrogen-bonded liquid crystalline materials: supramolecular polymeric assembly and 
the induction of dynamic function," Macromolecular Rapid Communication, vol. 22, pp. 797-814, 2001.

[21] H. K. Can, Z. M. O. Rzaev, and A. Güner, "Hydrogen (H)complex formation of maleic anhydride-acrylic acid (methyl acrylate) monomer system," Journal of Molecular Liquids, vol. 111, no. 1-3, pp. 77-84, 2004.

[22] C. Ladavière, T. Delair, A. Domard, C. Pichot, and B. Mandrand, "Studies of the thermal stability of maleic anhydride co-polymers in aqueous solution," Polymer Degradation and Stability, vol. 65, no. 2, pp. 231-241, 1999.

[23] R. K. Bund and R. S. Singhal, "An alkali stable cellulase by chemical modification using maleic anhydride," Carbohydrate Polymers, vol. 47, no. 2, pp. 137-141, 2002.

[24] L. Veron, M.-C. de Bignicourt, T. Delair, C. Pichot, and B. Mandrand, "Syntheses of poly[N-(2,2 dimethoxyethyl)-Nmethyl acrylamide] for the immobilization of oligonucleotides," Journal of Applied Polymer Science, vol. 60, no. 2, pp. 235-244, 1996.

[25] N.-J. Lee, Y.-A. Kim, S.-H. Kim, W.-M. Choi, and W.-J. Cho, "Syntheses and biological activities of $\mathrm{N}$-alaninylmaleimide and its polymers," Journal of Macromolecular Science A, vol. 34, no. 1, pp. 1-11, 1997.

[26] N. P. Desai and J. A. Hubbell, "Solution technique to incorporate polyethylene oxide and other water-soluble polymers into surfaces of polymeric biomaterials," Biomaterials, vol. 12, no. 2, pp. 144-153, 1991.

[27] S. Dinçer, A. Tuncel, and E. Pişkin, "A potential gene delivery vector: N-isopropylacrylamide-ethyleneimine block copolymers," Macromolecular Chemistry and Physics, vol. 203, pp. 1460-1465, 2002.

[28] V. Bulmuş, S. Patr, S. A. Tuncel, and E. Pişkin, "Stimuliresponsive properties of conjugates of $\mathrm{N}$-isopropylacrylamideco-acrylic acid oligomers with alanine, glycine and serine mono-, di- and tri-peptides," Journal of Controlled Release, vol. 76, no. 3, pp. 265-274, 2001.

[29] B. Kyu Kim, S. Yun Park, and S. Jin Park, "Morphological, thermal and rheological properties of blends: Polyethylene/nylon-6, polyethylene/nylon-6/(maleic anhydride-g-polyethylene) and (maleic anhydride-g-polyethylene)/nylon-6," European Polymer Journal, vol. 27, no. 4-5, pp. 349-354, 1991.

[30] C. A. Lucchesi, P. J. Secrets, and C. F. Hirn, Standart Method of Chemical Analysis, Krieger Publishing Company, New York, NY, USA, 1975.

[31] G. A. Jeffrey, An Introduction to Hydrogen Bonding, Oxford University Press, New York, NY, USA, 1997.

[32] P. V. Shibaev, S. L. Jensen P Andersen et al., "Multicomponent hydrogen-bonded liquid crystalline mixtures," Macromolecular Rapid Communications, vol. 22, pp. 493-497, 2001.

[33] M. M. Coleman and P. C. Painter, "Hydrogen bonded polymer blends," Progress in Polymer Science, vol. 20, no. 1, pp. 1-59, 1995.

[34] A. A. El'Saied, S. Y. Mirlina, and V. A. Kargin, "Copolymerization of unsaturated mono- and dibasic acids. The possibility of controlling copolymer composition," Polymer Science U.S.S.R, vol. 11, no. 2, pp. 314-328, 1969.

[35] T. Kelen and F. Tüdös, "Analysis of the linear methods for determining copolymerization reactivity ratios. I. A new improved linear graphic method," Journal of Macromolecular Science Chemistry A, vol. 9, pp. 1-27, 1975.

[36] M. Dube, R. A. Sanayei, A. Penlidis, K. F. O’Driscoll, and P. M. Reilly, "A microcomputer program for estimation of copolymerization reactivity ratios," Journal of Polymer Science A, vol. 29, no. 5, pp. 703-708, 1991.
[37] C. W. Pyun, "Comonomer and sterosequence distributions in high polymers," Journal of Polymer Science A, vol. 8, no. 7, pp. 1111-1126, 1970.

[38] T. Alfrey and C. C. Price, "Relative reactivities in vinyl copolymerization," Journal of Polymer Science, vol. 2, pp. 101-106, 1947.

[39] L. J. Young and G. Ham, High Polymers-Copolymerization, Interscience, New York, NY, USA, 1964.

[40] V. Ozturk and O. Okay, "Temperature sensitive poly (N-tbutylacrylamide-co-acrylamide) hydrogels: synthesis and swelling behavior," Polymer, vol. 43, no. 18, pp. 5017-5026, 2002.

[41] V. Bulmus, S. Patır, S. A. Tuncel et al., "Conjugates of poly(Nisopropyl acryl amide-co-acrylic acid) with alanine mono-, diand tri-peptides," Journal of Applied Polymer Science, vol. 88, pp. 2012-2019, 2003.

[42] N. S. Save, M. Jassal, and A. K. Agrawal, "Stimuli sensitive copolymer poly(N-tert-butylacrylamideran-acrylamide): synthesis and characterization," Journal of Applied Polymer Science, vol. 95, no. 3, pp. 672-680, 2005.

[43] P. Bajaj, T. V. Sreekumar, and K. Sen, "Effect of reaction medium on radical copolymerization of acrylonitrile with vinyl acids," Journal of Applied Polymer Science, vol. 79, pp. 1640-1652, 2001.

[44] A. K. Bajpai and A. Giri, "Swelling dynamics of a macromolecular hydrophilic network and evaluation of its potential for controlled release of agrochemicals," Reactive and Functional Polymers, vol. 53, no. 2-3, pp. 125-141, 2002. 

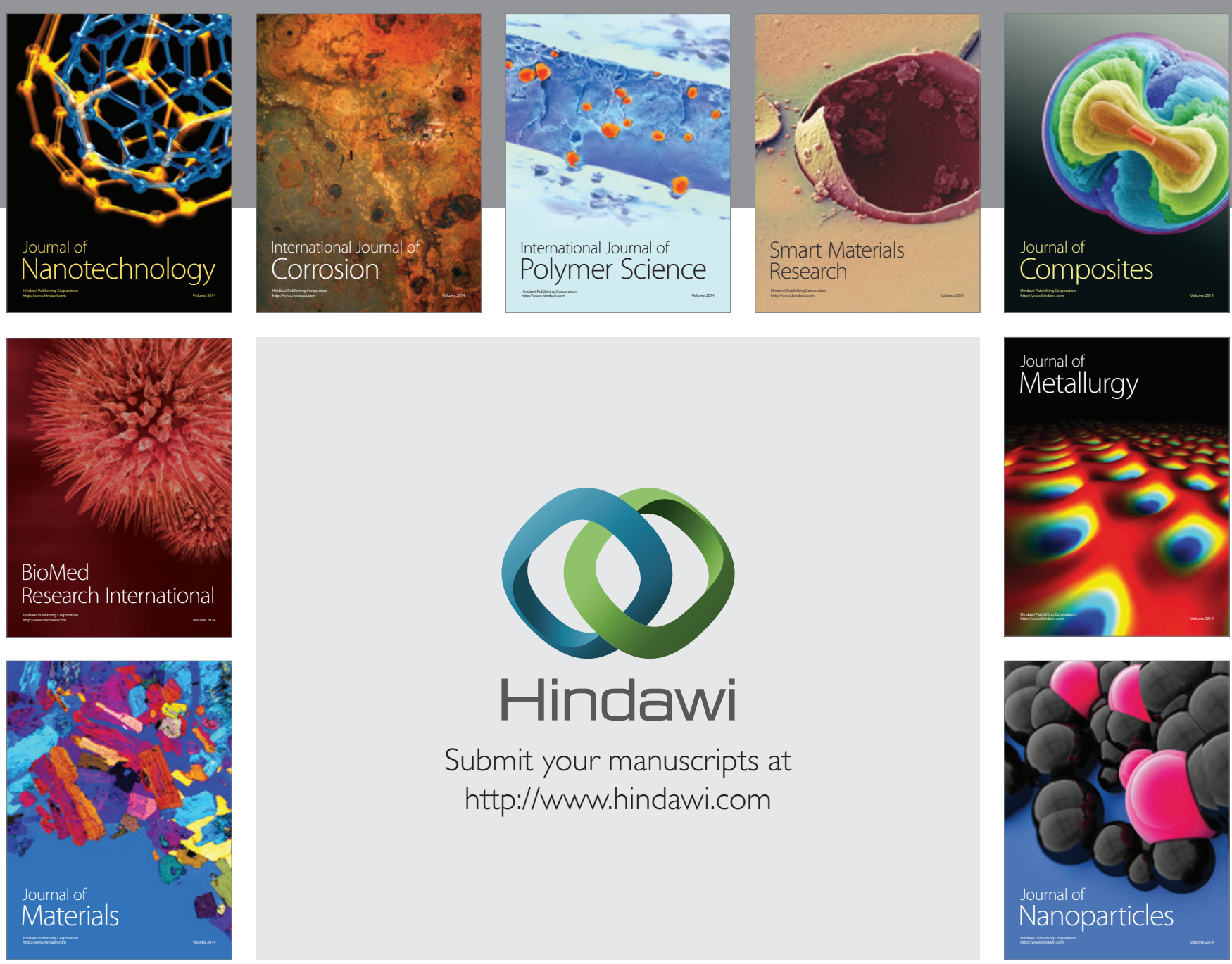

Submit your manuscripts at http://www.hindawi.com
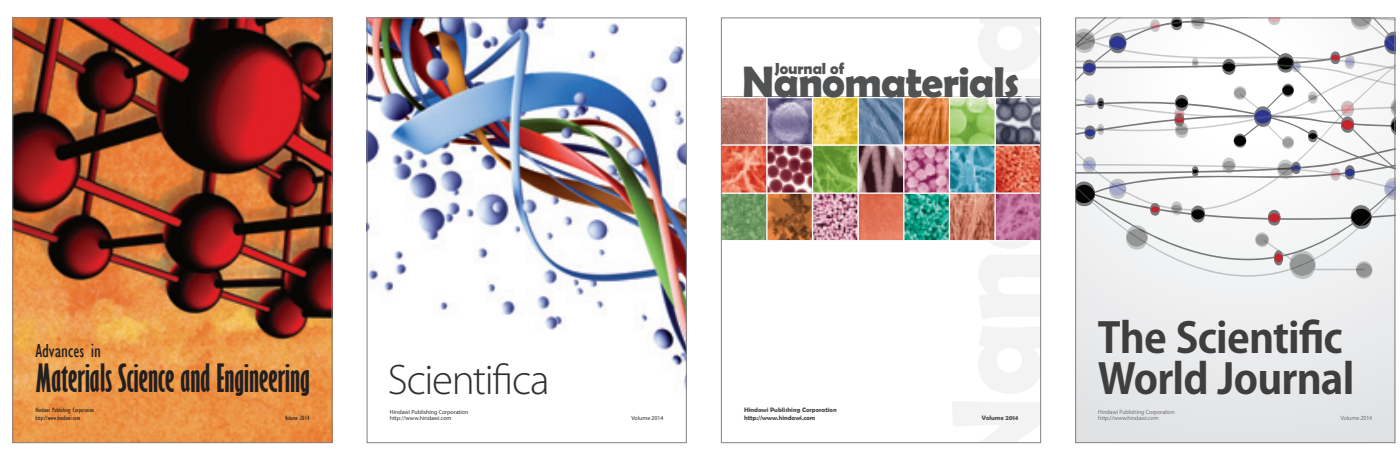

\section{The Scientific World Journal}
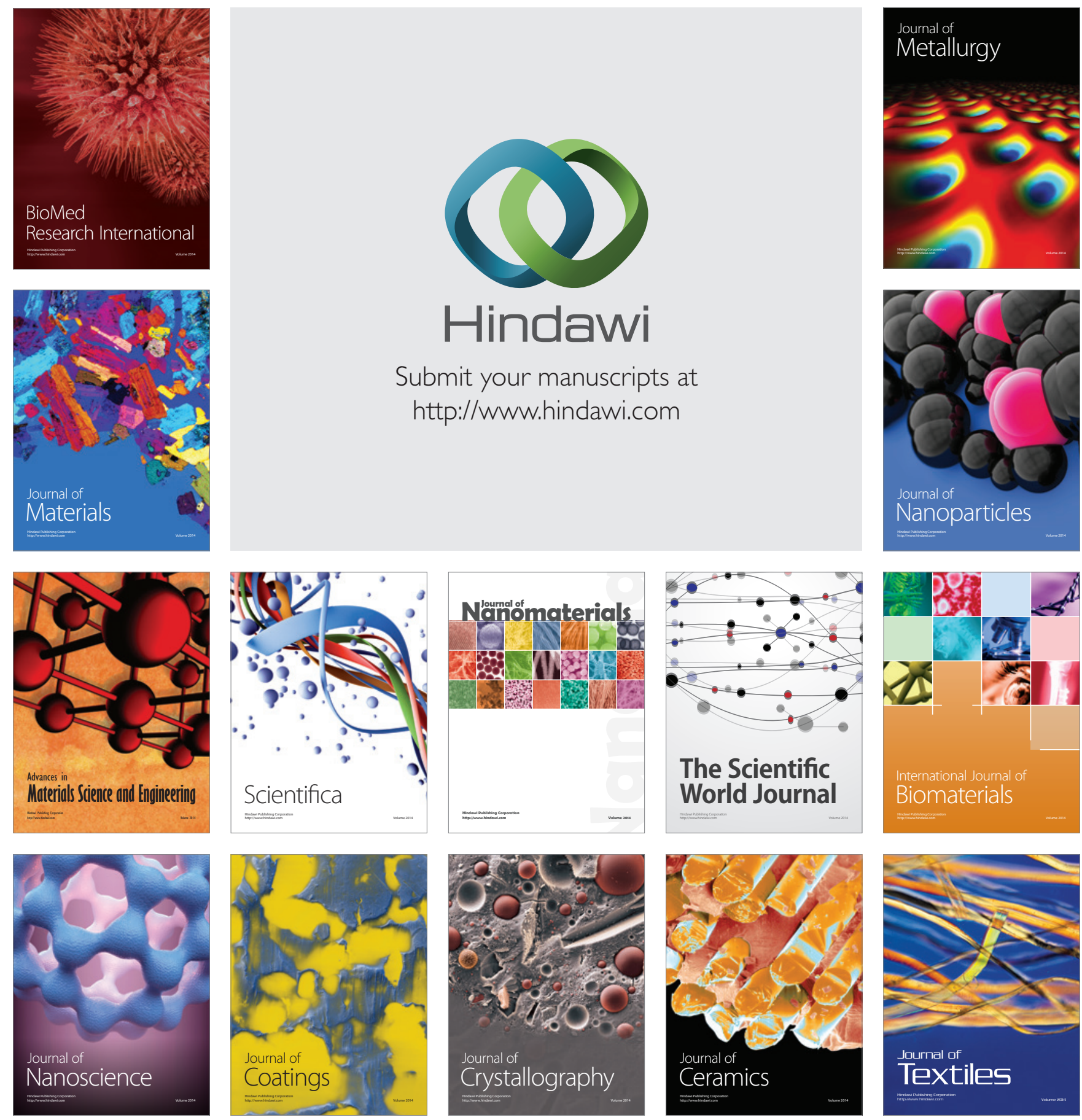